\title{
My one-year perspective as editor-in-chief of DDTR
}

\section{María José Alonso ${ }^{1}$}

Published online: 1 May 2020

(C) Controlled Release Society 2020

One year ago, I communicated to you how honored I am to have accepted the position of Editor-in-Chief of Drug Delivery and Translational Research (DDTR), published by Springer Nature. Now, I would like to give you my perspective about the journal achievements and prospects.

$D D T R$, an official journal of the Controlled Release Society (CRS, Inc.), leans on the extraordinary service of scientists affiliated with the CRS, many of whom are past or current members of the Board of Directors and other committees (e.g., International Committee, assembling CRS chapters from around the globe; and Focus Groups specialized in specific research topics).

In 2019, among 546 articles submitted, 89 articles were published in 6 issues. Since October 2019, we have started the selection of the best article published in each individual issue:

- Article of 2019 Oct Issue. Transungual drug delivery using laser technology

https://rdcu.be/bTog1

- Article of 2019 Dec Issue. New drug delivery immunotherapy approaches

https://rdcu.be/bWFVn

- Article of 2020 Feb Issue. Clinical applications of formulated natural compounds

https://rdcu.be/b1fCl

- Article of 2020 Apr Issue. Brain delivery and rare diseases

María José Alonso

mariaj.alonso@usc.es

1 University of Santiago de Compostela, Santiago de Compostela, Spain https://link.springer.com/content/pdf/10.1007/s13346-01900683-6.pdf

A very special recognition is given by the $D D T R$ editorial board to the best article published in 2019, which is recognized with a special award given by the CRS. This article has been featured in the DDTR web and deals with photodynamic therapeutic strategies using nanoparticles:

https://link.springer.com/content/pdf/10.1007/s13346018-00610-1.pdf

The Oral Drug Delivery Focus Group, represented by Aaron Anselmo, has also contributed by selecting the best article published in 2019 in the field of oral drug delivery. This article has been featured in the DDTR web and describes orally administered self-micro emulsifying drug delivery systems:

https://link.springer.com/content/pdf/10.1007/s13346019-00619-0.pdf

These articles, free-access for up to 2 months, have been featured by the recognized authors with help from our eMedia Editor, Prof. Jung Soo Suk. Please find on our website these selected articles and enjoy reading these important contributions.

Another special contribution from the Focus Groups of the CRS, namely the Focus Group on Nanomedicine and Nanoscale Delivery is a special issue entitled "Fundamentals of Nanomedicines Towards Clinical Translation" edited by Prof. Bruno Sarmento to be published in June 2020.

The Local Chapters of the CRS have also been represented in this year's activities. In particular, the Indian Local Chapter has contributed (A. Schroeder, V. Patravale, P. Elchidana, Editors) a special issue entitled "Drug Delivery Systems: from Basic Science to Clinical Translation", which reflects the important involvement of the Indian drug delivery community in the DDTR journal.

We have also started the implementation of our "Inspirational Notes", which are intended to provide an easy-to-read view of relevant concepts, ideas, and products. You will benefit from these notes through a free-access dissemination link available at the CRS and Springer web pages. Please, find our Note on Contraceptive technologies for 
global health: https://link.springer.com/content/pdf/10.1007/ s13346-020-00726-3.pdf

My vision for the next phase of the journal is to attract contributing authors that will result in DDTR being recognized globally as the journal of reference for drug delivery research.

Now we are facing an unprecedented crisis associated to a significant health challenge, and scientists must play an important role. Contributions from Drug Delivery scientists will be pivotal for advancing in the treatment of infectious diseases, going from the diagnosis, prevention and treatment of diseases. I invite DDTR readers to submit articles in this field with the commitment to accelerate the evaluation process and make the results available to the public in a short-time frame.

These and future achievements are possible thanks to the dedication of our outstanding team of editors and a highly responsive editorial board. I am very thankful to all of them and look forward to extend our contribution to the drug delivery community.

Publisher's Note Springer Nature remains neutral with regard to jurisdictional claims in published maps and institutional affiliations. 